\title{
Obstructive uropathy after pan-proctocolectomy for ulcerative colitis
}

\author{
M C WILSON, A R BERRY, T J MCNAIR, AND J W W THOMSON \\ From Chalmers Hospital, Edinburgh
}

SUMMARY We report two cases of pan-proctocolectomy for ulcerative colitis who some time postoperatively developed an obstructive uropathy with the clinical and radiological features of retroperitoneal fibrosis. The incidence of this complication appears to be around $10 \%$ and the possibility of such a diagnosis should be borne in mind in any patient who has non-specific symptoms after surgery for ulcerative colitis.

Direct operative damage to the ureter is a wellrecognised complication of colonic surgery which usually presents at operation or shortly afterwards. $^{1-5}$ There is a more insidious form of benign ureteric obstruction similar to retroperitoneal fibrosis which may appear after surgery on the colon and which has been reported from three centres. ${ }^{6-8}$ We present two cases who developed this type of ureteric obstruction after pan-proctocolectomy for ulcerative colitis during a 10 year period (1970-79) when 29 other patients underwent identical surgery with no upper urinary tract problems.

\section{Case 1}

In 1975, a 37 year old male newsagent presented with ulcerative colitis, medical control was ineffective, and in 1976 uneventful pan-proctocolectomy was performed by one of the authors (JWWT). Recovery was unremarkable but routine cystometrogram on the 10th day showed an atonic bladder. After a course of bethanochol chloride normal bladder tone and sensation were demonstrated and normal micturition established. A month later he was readmitted with acute retention of urine, fever, and right loin pain. Bladder catheterisation demonstrated a sterile residual urine volume of $1100 \mathrm{ml}$, but despite continuous bladder drainage for five days the loin pain persisted. There was no change in blood biochemistry but an intravenous pyelogram showed bilateral hydronephrosis with medial displacement of the middle third of both ureters.

At operation a dense band of fibrous tissue was

Received for publication 24 March 1980 found to pass in front of the sacrum and involve both ureters. Ureterolysis was performed and steroids continued for a month in the hope of preventing further fibrosis. Subsequent intravenous pyelography and isotope renograms have remained normal at follow-up after four years, bladder and sexual function having recovered fully in the early months after operation.

\section{Case 2}

A 29 year old housewife presented with ulcerative colitis in 1971. Medical control was achieved at first but, because of repeated relapse, an elective pan-proctocolectomy was performed in 1979 by one of the authors (TJMcN). Recovery was uneventful but routine cystometrogram showed no voiding contractions of the bladder. The urinary catheter, however, was removed and normal micturition established with no residuum. The patient was allowed home on the 17th day post-operatively.

Two weeks later the patient was readmitted with fever and right loin pain worse on deep inspiration. Intravenous pyelography showed a dilated left renal pelvis and medial displacement of the left ureter while only a renogram was demonstrated in the right kidney. The blood urea concentration, which had been normal at $2.7 \mathrm{mmol} / 1$, rose to $12.9 \mathrm{mmol} / \mathrm{l}$. Conservative treatment was pursued by passing bilateral ureteric catheters through a cystoscope to act as splints which were left in situ for two months. Oral steroid treatment was continued for two months in an attempt to prevent further fibrosis. After two months one ureteric catheter fell out and the other was removed. Sub- 
sequent intravenous pyelogram and isotope renograms have remained normal at four months.

\section{Discussion}

Retroperitoneal fibrosis may arise as an idiopathic disease or as the result of certain drugs. ${ }^{9}$ Neither of our cases received drugs likely to cause retroperitoneal fibrosis. In a recent series of 12 cases of ulcerative colitis with obstructive uropathy eight were found to follow surgery and it was suggested that retroperitoneal inflammation might be the cause. ${ }^{7}$ Inflammatory changes were considered to be the cause of the obstruction in our cases.

Ureteric obstruction in Crohn's disease has been well described but the literature suggests that ureteric obstruction occurs rarely in ulcerative colitis. ${ }^{9}$ In our series obstructive uropathy would appear to affect one in 15 patients undergoing pan-proctocolectomy and a recent series showed a higher incidence of one in six patients. ${ }^{8}$

On the basis of only two case reports no recommendations can be made concerning treatment of obstructive uropathy in ulcerative colitis but the current literature appears to favour a conservative approach. ${ }^{89}$ The role of steroids or antibiotics has not been evaluated and in our cases steroids were used empirically.

Many clinicians are not aware of the possibility of obstructive uropathy in patients suffering from ulcerative colitis and it is clearly an important diagnosis to consider, particularly in those patients undergoing pan-proctocolectomy.

\section{References}

${ }^{1}$ Badenoch AW. Injuries of the ureter. Proc Roy Soc Med 1958; 52: 101-8.

'Spence HM, and Boone T. Surgical injuries to the ureter. JAMA 1961; 176: 1070-76.

${ }^{3}$ Goligher JC. Surgery of the anus, rectum and colon. London: Ballière, Tindall and Cassell; 1967.

${ }^{4}$ Higgins CC. Ureteral injuries during surgery. A review of 87 cases. JAMA 1967; 199: 82-8.

${ }^{5}$ Carlton CE Jr, Scott R Jr, Guthrie AG. The initial management of ureteral injuries: a report of 78 cases. J Urol 1971; 105: 335-40.

${ }^{6}$ Chisholm ER, Hutch JA, Bolomey AA. Bilateral ureteral obstruction due to chronic inflammation of the fascia around the ureters. $J$ Urol $1954 ; 72$ : 812-6.

${ }^{7}$ Klevmark B, Nygaard K. Reversible ureteral stenosis as a delayed complication of operation on the colon and rectum. Acta Chir Scand 1975; 141 : 153-9.

${ }^{8}$ Fleckenstein P, Knudsen L, Pedersen E, Marcussen H, Jarnum S. Obstructive uropathy in chronic inflammatory bowel disease. Scand J Gastroenterol. 1977; 12: 519-23.

${ }^{2}$ Lepor H, Walsh PC. Idiopathic retroperitoneal fibrosis. J Urol 1979; 122: 1-6. 